\title{
Smart Services as Cultural and Historical Heritage Information Assistance for Museum Visitors and Personnel
}

\author{
Dmitry KORZUN ${ }^{1}$, Svetlana YALOVITSYNA ${ }^{2}$, Valentina VOLOKHOVA ${ }^{3}$ \\ ${ }^{1}$ Department of Computer Science, Petrozavodsk State University, 33 Lenin Ave., \\ Petrozavodsk, Republic of Karelia, Russia \\ 2 Institute of Linguistics, Literature and History, Karelian Research Centre of Russian \\ Academy of Sciences, 11 Pushkinskaya St., Petrozavodsk, Republic of Karelia, Russia \\ 3 Department of Russian History, Petrozavodsk State University, 33 Lenin Ave., Petrozavodsk, \\ Republic of Karelia, Russia \\ dkorzun@cs.karelia.ru, jalov@yandex.ru, vavolokhova@yandex.ru
}

\begin{abstract}
Museums are now digitally enhanced based on smart information services that assist visitors and personnel. Cultural and historical heritage $(\mathrm{CHH})$ is perceived in a personalized and cognitive way. New knowledge is created using active participation of the users themselves. In this paper, we overview the smart museum concept developed at Petrozavodsk State University (PetrSU). We consider possible information services for effective CHH preservation and transmission within a digitally enhanced museum. The studied services can be further extended to assist in the museum research activity by discovering information for applying human expertise and for reasoning new knowledge. The basic information representation model is a semantic network, which reduces data mining to ranking in a linked structure. As a case study the services for the History Museum of PetrSU are elaborated and discussed.
\end{abstract}

Keywords: cultural and historical heritage, smart museum, information services, digital assistance, semantic network, data mining

\section{Introduction}

Our society has entered into the digital era, and the term "smart" becomes widespread in relation to modern technologies (Augusto et al., 2013). We limit our scope with smart information and communication technology (ICT), which has multi-disciplinary character, and its "smart" aspects are now emerging in many domains, including social and cultural ones (Korzun, 2016b). Cultural and historical heritage (CHH) is a domain where new ICT and digital services have a special impact on people approach to preservation, transmission, and research (Chianese et al., 2015), (Kalus, 2007). CHH entities 
can be considered in terms of various properties; to name some examples: works of fine and applied arts or folk crafts, archaeological, architectural, ethnographic or historical sites and complexes, samples of park art and landscape architecture, industrial, documental or audio-visual heritage, spoken tradition and language or literary values, customs, rituals, celebrations and beliefs, music, songs and dances, culinary and ethnological traditions, folk games and sports.

The presented work extends our conference publication (Korzun et al., 2018) on the smart museum concept. We continue our research in the smart museum development. In particular, the semantic-driven design of service-oriented information systems (for various problem domains) was initially proposed in (Korzun, 2014), (Korzun, 2016b) and further extended in (Korzun, 2016a). The semantic infrastructure solutions for making $\mathrm{CHH}$ knowledge usable and creatable by museum visitors and professionals were discussed in (Korzun et al., 2017). Prototype development and its initial experiments were presented in (Marchenkov et al., 2017)

We consider smart museum information services that can be developed based on a semantic network interlinking the museum $\mathrm{CHH}$ collection, including knowledge acquired from visitors and museum personnel. The semantic network enhances the existing collection operating with digital representations of exhibits, descriptions of $\mathrm{CHH}-$ valued objects and facts as well as with any available fragments of $\mathrm{CHH}$ knowledge. This network is subject to data mining needed for selection of appropriate information as a result provided by services. Our case study is the History Museum of Petrozavodsk State University (PetrSU) in respect to everyday life history; the museum provides the pilot testbed to analyze the information services.

The rest of the paper is organized as follows. Section 2 overviews the recent progress in smart museum development. Section 3 introduces our smart museum concept, which is essentially based on information services. Section 4 describes mathematical methods that our approach applies in services development. Section 5 discusses particular smart museum information services using the case study of the History Museum of PetrSU. Finally, Section 6 concludes the paper.

\section{Development Problem}

\subsection{Basic Museum Activity}

Museum activity has many various goals and implementation forms. Our previous work (Korzun et al., 2018) showed that the whole spectrum of museum applicability needs in $\mathrm{CHH}$ domain can be considered from the following three points.

Preservation (and knowledge promotion) The museum digitally preserves information about the collected $\mathrm{CHH}$ entities, in addition to physical preservation (Simou et al., 2017). The linked-oriented forms of $\mathrm{CHH}$ information preservation showed their effectiveness in museums, e.g., see (Ruotsalo et al., 2013), (Mouromtsev et al., 2015). The collected information and its stored interlinked knowledge is subject to promotion when various audiences are advertized and involved to $\mathrm{CHH}$ knowledge consumption and use. 
Modern history is a special interest example. A museum visitor can be a participant of the event presented in the exhibition. People's living memory is sometimes the only or at least the most accessible source of information about the events of unofficial history (family holidays and traditions, everyday household practices, ordinary citizen opinion to the events of "great history", etc.).

Transmission (and knowledge mastering) A museum environment provides an operational space for education activity (Amato et al., 2017). In addition to self-education when a person (or group) individually makes $\mathrm{CHH}$ studies, enhanced education activity is possible, which includes thematic training or even pedagogical interaction. This activity needs context-aware information search for effective knowledge consumption and use. In particular, CHH information is visualized on nearby screens, and the users make interaction and storytelling with smart exhibits (Vassilakis et al., 2018).

This form for $\mathrm{CHH}$ presentation makes the educational activity interesting for new categories of visitors, especially children and youth. Representatives of the elder generation also note that personal active participation in the selection of information for visualization makes the visit to the museum more interesting and attracting. Basically, each visitor concentrates more on the subjects of study and less on the search function for source information.

Research (and knowledge enriching) A CHH researcher needs many basic information facts to create a fused picture from them and to interpret the value of this picture (Korzun et al., 2017). The initial information corpus is large, and the search cannot be done manually. In the transmission above, an information fragment is found. In the research, information fragments having potential knowledge are needed. The particular knowledge is created by an expert and enriches the museum collection.

The search uses the multitude of context relations between exhibits. Each individual exhibit has fragmentary information. The whole picture of a studied $\mathrm{CHH}$ phenomenon can be created when the relationship between individual facts is detected. Then new hypotheses can be built and grounded conclusions are drawn.

\subsection{Museum Digitalization}

A lot of efforts have been made already in museum digitalization and the consequent service-oriented assistance of museum visitors and personnel. Museum databases store the information part of the collection to track all knowledge related to and about the $\mathrm{CHH}$ objects (exhibits) and to ensure the long-term safety and sustainability of those objects within the museum's care. The basic function is an electronic archive (catalogue) administered by museum personnel. The semantics are not reflected explicitly in the information collections. No explicit intelligence in searching and processing the collected descriptions is provided to museum visitors (at most they can straightforwardly browse the content). Its extensions lead to "smart services", emphasizing a certain intelligence level in service construction and delivery.

In the early 1980s, the International Council of Museums (ICOM) stated the necessity of information technologies in museum activities. The Council created a specialized 
unit-the International Committee for Documentation (CIDOC), which included representatives of international organizations and individual scientists professionally working with the problems of museum informatics. In particular, the Committee developed the ontological approach to semantic interoperability of CHH metadata (Doerr, 2003).

The recent ICT progress (including Internet of Things, IoT) supports development of on-site personalized services for museum visitors. A visitor has a personal mobile device (e.g., smartphone) accessing relevant information about surrounding exhibits and in a personalized and cognitive way (Amato et al., 2017). The information flow goes from digital cultural heritage to visitors. SMARTMUSEUM system (Ruotsalo et al., 2013) provides explanatory description and multimedia content associated with individual objects. A museum exhibition can tell a story (Vassilakis et al., 2018). Objects for a visitor to study can be recommended based on the user profile and context information. Additional content about an object can be retrieved from the Web. The on-site visit boundaries of $\mathrm{CHH}$ experience at the museum can be extended to assist the visitors during pre-visit planning and to follow up with post visit memories and reflections (Kuflik et al., 2015).

Modern ICT makes it relatively cheap and easy to "personalize" products and services for each individual user, or to use "mass personalization" to create the illusion of individual attention. This trend appears in the three areas appropriate for museums: creating personalized products, filtering personalized content, and creating personalized experiences. The audience of the future (formed by the wider market) can expect that the products, communications, and experience of museums will be adapted to their interests and needs. People accustom to personalized services from both government agencies and commercial companies ${ }^{4}$.

The richness of museum activity forms accelerates the visitor to independently develop own familiarization with the artifacts, i.e., "finding" those objects that satisfy her/his interest. Personalized access to collections, alerts, agendas, travel offers, and audio guides are just a few examples of the various applications already developed by museums around the world e.g., see (Bowen \& Filippini-Fantoni, 2004). The first examples of web-oriented personalization in the museum context were started in the late 1990s. For instance, the SAGRES system (Moraes et al., 1999) is an educational environment that presents the museum's content adapted to the users characteristics (capacities and preferences). Based on information provided directly by the user or by the teacher (for students), the system determines the group of links appropriate to the user(s) and presents them in a personalized web page.

Museum information services support people to be involved into the process, e.g., using feedback when visitors leave posts on exhibits (to read by other visitors) or evaluate exhibits (collaborative activity). IoT-enabled location-based services make possible shortening the information distance between objects in cultural spaces and their visitors (Chianese et al., 2015). Physical or virtual CHH objects can interact with people, environment, other objects, and transmitting the related information to users through multimedia facilities. Services become oriented to personalized recommendations when

\footnotetext{
${ }^{4}$ See blog discussion "It's Personal: one size does not fit all" at https://www.aamus.org/2015/05/01/its-personal-one-size-does-not-fit-all/ by Elizabeth Merritt, American Alliance of Museums, posted on May 1, 2015
} 
the system captures the event the visitor studies a CHH object. A set of "close" objects can be selected, ranked, and arranged to be provided to the visitor for subsequent study.

Visitors are rich sources of new information about $\mathrm{CHH}$ objects, which is captured using annotations (Alzahrani et al., 2014). An added annotation enhances digital object memory, when the object stores data about itself and links other objects (Torre, 2013). In a museum environment, object memory can store information about the provenance of the artifact, about its history, and the flow of comments generated by visitors while interacting with the artifact.

\section{Information Services}

Smart museum extends the information archive function. The extension is supported with Internet-based services, acting as effective providers of $\mathrm{CHH}$ information. Mobile multimedia, ambient intelligence, machine vision, augmented reality, and other IoTrelated technologies lead to advanced museum information services for effective $\mathrm{CHH}$ preservation, transmission, and research.

\subsection{Smart Museum Services}

Our vision on the ICT use in a smart museum considers the following services that provide visitors or personnel with information for assisting their activity.

Smart navigation The museum visitors are notified (e.g., smarthones) about the recent situation in exhibition rooms (e.g., occupancy level, absent exhibits, or ongoing entertainments). The navigation become context-aware and subject to effective and personalized decision-making, e.g., see (Ruotsalo et al., 2013).

Before visiting a museum, a potential visitor can use the mobile application or website to plan the visit. Inside the museum, a visitor can operate with digital information using one of the following ways. The first way employs a personal mobile device (own or rented), which can scan tags or to determine location. The second way is when a visitor can identify herself/himself on each exhibit with a biometric identifier (e.g., fingerprints, face detection) or a personal label (e.g., radio frequency identification-RFID). After the exhibition study, the visitor can further develop her/his experience using social media platforms such as Facebook or Tumblr (Schuster, 2013).

The CHIP project aimed at $\mathrm{CHH}$ information personalization based on bridging the gap between virtual and physical museum experience (Lora et al., 2007). The services support a museum visitor to create her/his profiles, to record artistic preferences and related cultural activities, and to use the data to develop personalized tours. The assumption is that a compelling personal experience would motivate more frequent use of the museum online resources and the museum expositions.

Quality evaluation Visitors and their activity form a rich source for qualitative analytics on the museum expositions (e.g., most visited rooms, high-interest exhibits and information, or popular routes). The museum monitors its own function and evaluate its 
efficiency, so adapting and personalizing the service provision to the user's needs, e.g., see (Lepouras et al., 2015).

Dallas Museum of Art received a grant to support new technology for audience engagement initiatives ${ }^{5}$. The project participants- The Denver Art Museum (DAM), Los Angeles County Museum of Art (LACMA), and Minneapolis Institute of Arts (MIA) represent diverse models of membership and admission common to major U.S. art museums, with both fee-based and free programs. Each museum exists in a large metropolitan region, has encyclopedic collections of art, and devotes significant resources to education programs focused on audience engagement. They will improve the system for compiling and analyzing data on visitor participation and document critical factors that have an impact on audience engagement at museums. The information is collected and analyzed on the strengths and weaknesses of museum programming and the degree to which audiences are connecting and engaging with an institution.

Multimodal interface Information provision is augmented using context and multimedia (e.g., visualization of interesting facts on a nearby screen, exhibit self-storytelling, or 3D modeling). That is, the transmission efficiency of preserved CHH knowledge to the visitor can be increased to the level similar to the personal assistance by an expert, e.g., see (Vassilakis et al., 2018).

The VilVite science center (Bergen, Norway) now invites visitors to personalize their experiences (Schuster, 2013). Visitors can use an RFID card to register, get a unique visitor ID, initiate experiments, and retrieve the experience on the VilVite website after the visit. The information is also available on terminals in the exhibition area. Video clips, pictures, and other data generated by the visitor are thus available after the visit for educational purposes or for sharing on social media.

Collective intelligence Involving visitors to $\mathrm{CHH}$ preservation within their museum activity (e.g., impression sharing, gamification, or collaborative estimates). The museum collection is enriched by information provided by visitors themselves, including knowledge created collaboratively. This property of social networks extends the museum to a cyber-physical-socio system, e.g., see (Amato et al., 2017).

University of Geneva developed a semantic digital library system ${ }^{6}$ for storing and interconnecting urban models and resources. Each model is semantically described by linking it to the concepts it deals with. The digital library also stores interconnection resources that indicate how to interconnect two models. The library is equipped with a web interface through which the users import models and resources, search and compare them, build and store interconnection resources. The usability and usefulness of the system are demonstrated by using it to assemble a 3D visualization tool that displays (within a 3D city model) results obtained from other models, such as air quality, transport, or energy consumption.

\footnotetext{
${ }^{5}$ See https://www.dma.org/press-release/dallas-museum-art-receives-institute-museum-andlibrary-services-grant

${ }^{6}$ See http://www.unige.ch/icle/Recherche/SEMDl_en.html
} 


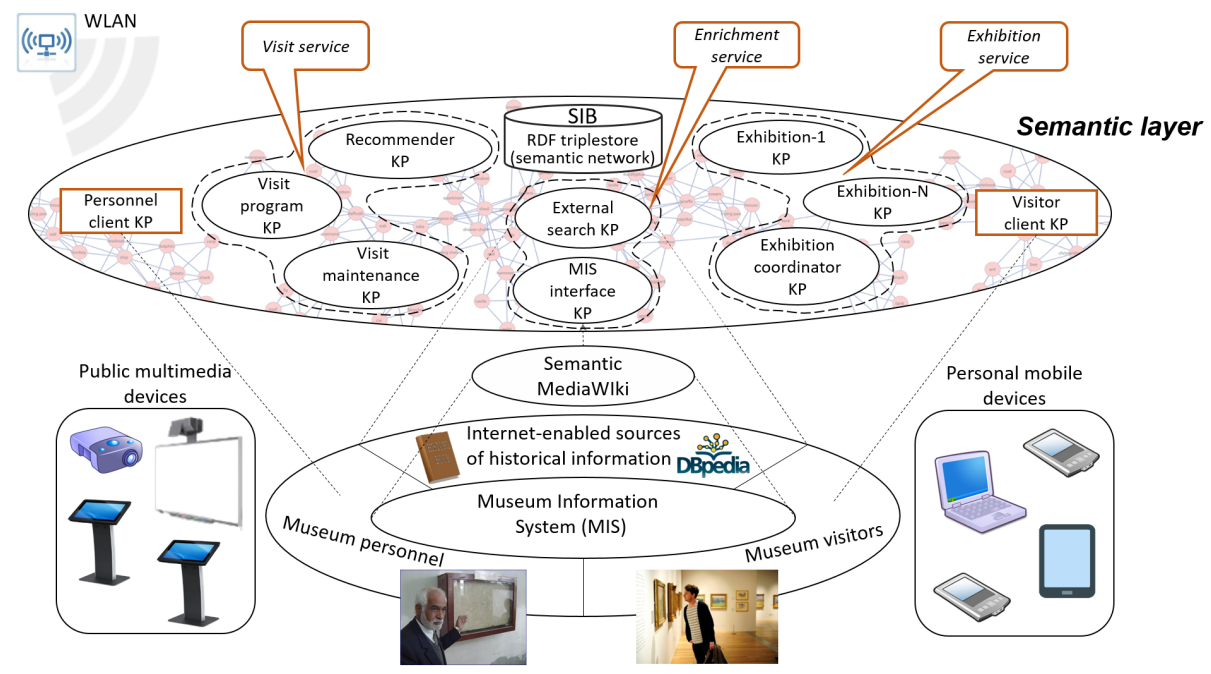

Fig. 1. Concept view on a smart museum system

Collective intelligence is also associated with the refinement and expansion of information in the Internet by improving the work with tags. An example is MOAT tool ${ }^{7}$ (Meaning of a Tag) that provides a Semantic Web framework to publish semanticallyannotated content from free-tagging. MOAT provides a way for users to define meaning(s) of their tag(s) using URIs of Semantic Web resources (such as URIs from DBpedia, GeoNames and many other knowledge bases), and then annotate content with those URIs rather than free-text tags. This approach can be used in a museum for expertise and analysis of the information added by users and its inclusion decision into the existing museum collection.

\subsection{Semantic Integration}

The need of semantic integration of available $\mathrm{CHH}$ knowledge for creating smart museum information services has been already understood (Smirnov et al., 2012), (Mouromtsev et al., 2015). It supports creating new exhibitions, working with visitors on a personal or mini-group level, contributing to the realization of their expectations.

A mediation layer is introduced for semantic integration where knowledge is derived based on a distributed set of multiple data sources, including such services as DBpedia (Bizer et al., 2009) and other services for semantic publishing, enrichment, search, and visualization (Mouromtsev et al., 2015), (Simou et al., 2017). We apply the semantic network model for integration of digital CHH content (Kalus, 2007), (Korzun et al., 2017), (Petrina et al., 2017).

Our concept view on a smart museum system is shown in Fig. 1. The example services Visit service, Enrichment service, and Exhibition service will be described further in Section 5. The following components are included.

\footnotetext{
${ }^{7}$ See https://www.w3.org/2001/sw/wiki/MOAT
} 
1. Ontological model for structural representation of collected CHH exhibits as well as their various descriptions and relations with other objects (on top of MIS).

2. The wiki system to transform the semantics from the collected records to the semantic network using experts and the ontological model.

3. The smart spaces approach for cooperative constructing and maintaining the semantic network by many dynamic participants.

4. Semantic algorithms for data mining in the constructed semantic network to take into account existing relations between collected exhibits and other $\mathrm{CHH}$ objects

In the considered case, an information service provides a search extend of the museum collection. The service aims at finding several the most appropriate information facts for a given problem. This property is close to the $k$-optimization approach (when several top solutions are used). To mention as examples, some particular semantic properties of such services are as follows.

- Semantic clustering: a set of thematically related objects.

- Semantic filtering: most appropriate descriptions for a given object.

- Semantic neighborhood: closely related objects for a given object.

The properties can be achieved based on certain information arrangements, when the order describes the relevance of information fragment. Mathematically, this way of data mining can be implemented using ranking models. Arranged information is provided with numerical rank values. Objects with similar ranks can be considered as forming a cluster. Highest-rank objects are selected in filtering. For a given objects, its rank-based neighborhood includes the objects having similar rank value.

\section{Semantic Data Mining}

A semantic network is created on top of the museum collection-descriptions from the various information sources (Korzun et al., 2017). Formally, a semantic network is a directed graph $G=(V, L)$ consisting of nodes (vertices set $V$ ) representing domain objects and links (edges set $L$ ) representing semantic relations. The nodes correspond to physical exhibits (digitally virtualized) and digital exhibits (e.g., electronic photos, scanned documents), associated events, persons, and other $\mathrm{CHH}$ objects. The links in $L$ reflect interrelation of the objects.

\subsection{Semantic Network}

The ontological model for the semantic network is defined by ontology $O$. First, $O$ describes a system of concepts $\left\{C_{i}\right\}_{i=1}^{n}$ (ontology classes) such that any particular node $v \in V$ (ontology class object, instance or individual) belongs to one or more concepts. Second, $O$ describes the interlinking structure for $L$, i.e., between which concepts a relation can be and possible types of such relations. The links represent the primary semantics. Third, $O$ describes attributes that $v \in V$ and $l \in L$ may have to reflect additional semantics (e.g., keywords).

Semantic network construction is implemented as a collective process (Petrina et al., 2017). On the one hand, many nodes $v$ are straightforwardly 
derived from existing museum records (e.g., collected in the museum information system) or correspond to descriptions available in various open sources (e.g., web pages or photos in the Internet). On the other hand, for nodes $v \in V$ the expert defines semantic relations (i.e., links $l \in L$ ) and their attributes.

An information service needs to find $k>0$ the most appropriate information facts. A fact can be a node $v \in V$, a link $l \in L$, or a connected graph structure $s$ in $G$ (e.g., a path from $u$ to $v$ can have $\mathrm{CHH}$-valued interpretation for some $u, v \in V$ ). This data mining can be reduced to the ranking problem when rank values $r_{v} \geq 0$ or $r_{l} \geq 0$ are associated with nodes or links. The higher rank the better is appropriateness of the information. The rank of a connected graph structure is calculated based on ranks of the composed nodes and links.

\subsection{Ranking Models}

We consider the following three classes of ranking methods (Petrina et al., 2017): 1) local ranking, 2) collaborative filtering, 3) structural ranking.

Local ranking Two or more objects are analyzed for similarity based on their content and overlapping of this content. In this case, the rank is computed in respect to some fixed node $u \in V$ and reflects distance of other nodes from $u$ :

$$
r_{v}(u)=1 / \rho(u, v)
$$

For instance, if $u$ and $v$ have sets $K_{u}$ and $K_{v}$ of annotating keywords then the rank reflects the size of overlapping $\left|K_{u} \cap K_{v}\right|$, i.e., the larger the number of shared keywords the higher is the similarity. In particular, if $u$ is the recent exhibit that the visitor studies then the information service can provide the highest rank nodes $v_{1}, \ldots, v_{k}$ as recommendation for the subsequent study.

Collaborative filtering: This ranking model assumes that many users generate opinions about each $\mathrm{CHH}$ object. The opinions are transformed to some community based score $r_{v}^{*}$ (normalized $0 \leq r_{v}^{*} \leq 1$ ). Then the scores can be combined with other ranking requirements. For instance,

$$
r_{v}=\alpha r_{v}^{*}+(1-\alpha)\left(1-\frac{d_{v}}{\max _{w \in W} d_{w}}\right)
$$

where $W \subset V$ is nodes of potential interest for the visitor, $d_{w}>0$ is a physical reachability metric for node $w, 0 \leq \alpha \leq 1$ is a tradeoff parameter between community scores and reachability.

In particular, if $W$ is a set of points of interest for the visitor and $d_{w}$ is the time for the visitor to reach $w$ from the current location then the information service can provide the highest rank nodes $v_{1}, \ldots, v_{k}$ as recommendation for the next object to study. 
Structural ranking This ranking model utilizes the connectivity properties of the semantic network $G$, similarly as it happens in the well-known PageRank algorithm for network analysis. For instance, node ranks $r_{u}$ for all $u \in V$ can be computed iteratively starting from some initial values $r_{u}^{(0)}$ :

$$
r_{u}^{(i+1)}=\alpha \sum_{l=(u, v) \in L} p_{v u} r_{v}^{(i)}+(1-\alpha) \pi_{u}
$$

where $p_{v u}$ is weight of the link $l=(u, v), 0 \leq \alpha \leq 1$ is the damping factor denoting the probability of following the connectivity structure of $G$, and $\pi$ is a jump probability vector for all $u \in V$.

In particular, if $p_{v u}$ are relative weight of $\mathrm{CHH}$ role of $v$ to $u$ then the information service can provide the highest rank nodes $v_{1}, \ldots, v_{k}$ as recommendation for the most $\mathrm{CHH}$-valued nodes to study.

\section{Case Study}

The History Museum of Petrozavodsk State University (PetrSU) is a typical small museum oriented to everyday life history (Korzun et al., 2017). Although the museum exhibition room is space-restricted the multimedia equipment enables effective visualization of information associated with exhibits, see Figs. 2 and 3.

More than 10 digital displays of various sizes with changing images of photographs, documents, newspaper articles from different eras of more than 75-year PetrSU history. Transformable table makes it easy to change the Museum space, making it comfortable for different forms of collaborative work activities. Some displays show video and audio interviews with the teachers of the University in different years. Exhibits presented on windows show everyday life history of teachers, researchers, and students. Some exhibits, despite their advanced age, can be experienced directly in the room. Old movies about PetrSU life in the 1970s and 1980s provide the necessary cultural and historical atmosphere.

Let us consider the three particular information services that we developed for pilot use in this museum. Visual design and user interface details of the presented smart museum information services were demonstrated in (Petrina et al., 2017). The generic role of the considered smart museum services is summarized in Table 1 (see also our concept view in Fig. 1 above).

Visit service The service constructs a personalized exposition of recommended exhibits for a visitor to study. Such a recommendation is a small set of selected objects from the presented ones in the museum exhibition room. This set $V_{U}$ is constructed from the available knowledge such that the set represents the most interesting facts for the particular visitor $u$ or their group $U$. This way, a visit program is constructed for a museum visitor before the visit. The service is also responsible for program adaptation during the visit depending on the preferences of the visitor and on the dynamically changing situation. 


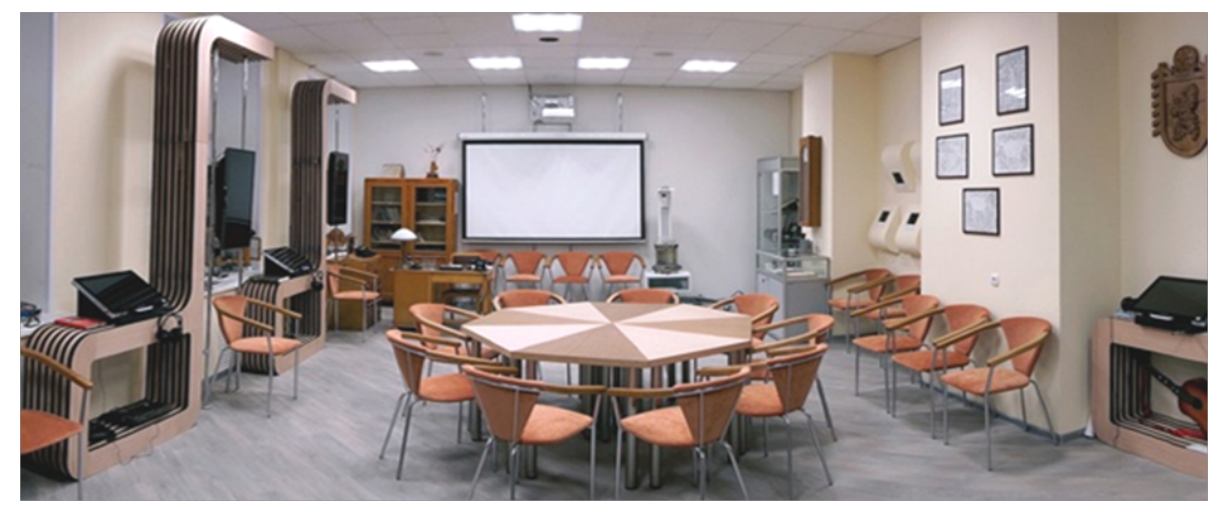

Fig. 2. History Museum of PetrSU: View on the exhibition room

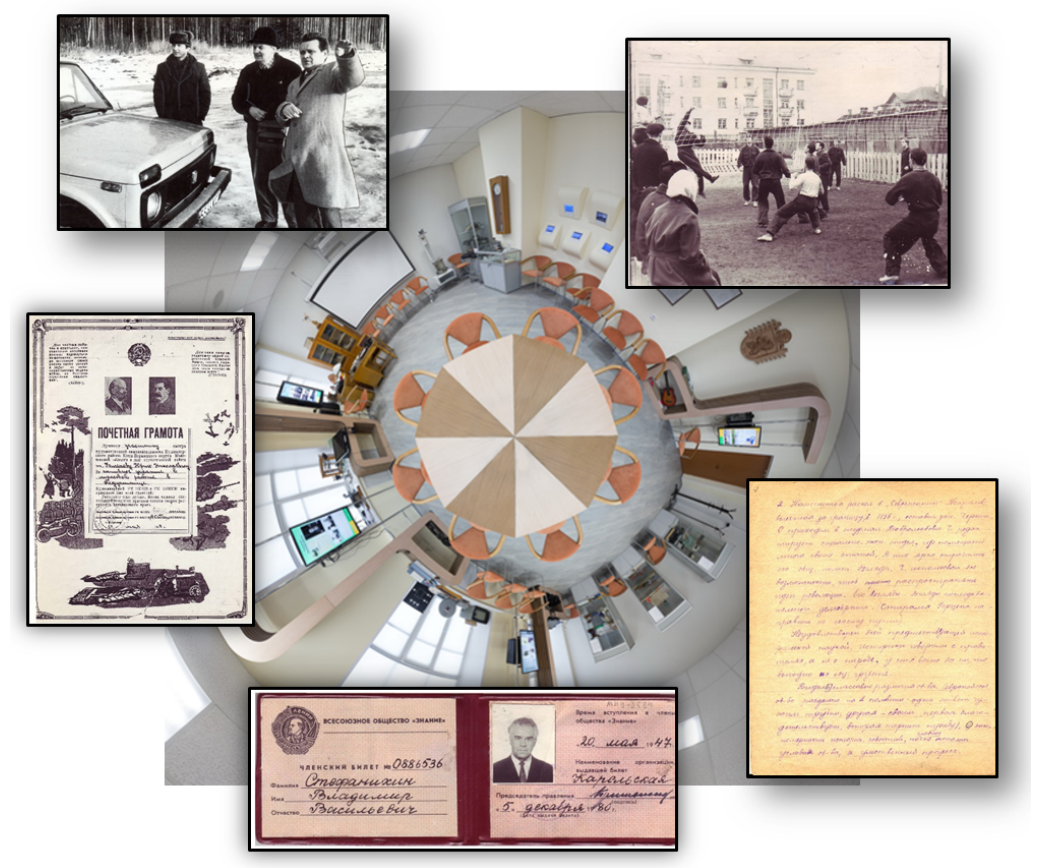

Fig. 3. Example digital content to augment observable exhibits

The Museum is a point from which the guest often starts introduction with PetrSU. According to psychologists, the memorization of new information occurs when the knowledge is associated with the existing one. The service discovers facts in the biography of Museum visitors and intersects them with facts from the University history or with persons who worked (working) in PetrSU. The educational function becomes 
Table 1. The role of smart services in respect to museum collection

\begin{tabular}{|l|l|l|l|}
\hline \multicolumn{1}{|c|}{ Service } & \multicolumn{1}{|c|}{ Visit service } & \multicolumn{1}{|c|}{ Exhibition service } & \multicolumn{1}{|c|}{ Enrichment service } \\
\hline \hline Preservation & Global scale structure & Local scale structure & $\begin{array}{l}\text { Community-based } \\
\text { collection }\end{array}$ \\
\hline Transmission & $\begin{array}{l}\text { Thematic navigation in } \\
\text { CHH knowledge } \\
\text { collection }\end{array}$ & $\begin{array}{l}\text { Personalized navigation } \\
\text { in semantic neighborhood } \\
\text { for given exhibit }\end{array}$ & $\begin{array}{l}\text { Involving the community } \\
\text { to the activity }\end{array}$ \\
\hline Research & $\begin{array}{l}\text { Structured global view } \\
\text { on CHH knowledge } \\
\text { collection }\end{array}$ & $\begin{array}{l}\text { Focused local view on } \\
\text { given fact within its } \\
\text { neighborhood }\end{array}$ & $\begin{array}{l}\text { Community resources } \\
\text { utilization and knowledge } \\
\text { analysis }\end{array}$ \\
\hline
\end{tabular}

more effective, making an almost personal approach to each visitor and improving the whole PetrSU image.

For the service delivery we developed a mobile application (for Android smartphones). Typical users are university graduates and lecturers, i.e., those who were or are direct participants of university life events. The user can provide such personalized information as sex, age, period of university study, hobby and interests, etc. Based on this information, the most appropriate exhibits are selected to recommend a personalized visit program. For instance, if the museum visitor is a student from Institute of Mathematics and Information Technology, then exhibits related to the mathematical education in PetrSU have higher rank.

Visit service uses exhibit ranks based on local ranking (although other ranking models can be applied as well). In particular, $r_{v}=1 / \rho(U, v)$, where the distance $\rho(U, v)$ shows semantic similarity of users $U$ to the exhibit $v \in V$. The $\mathrm{CHH}$ interests of the user are included into the user profile and can be represented in the node $u \in U$ in $G$. Objects in $V_{U}$ can be ordered into the visit program (i.e., implementing smart navigation), which is in turn visualized on the public screen in the museum room or on personal mobile devices of the users (i.e., implementing multimodal interface).

Exhibition service The service shows selected descriptions and visual information about the studied exhibits on exhibition touch screens or on personal mobile devices of the visitors. In fact, the service creates a kind of virtualization when a physical exhibition is augmented with digital representation (i.e., implementing multimodal interface). As in Visit service, Exhibition service acts as a recommender since the screens show the recommended (most interesting) facts derived from the available $\mathrm{CHH}$ knowledge for the current context and situation.

Therefore, in a small room many studies can be implemented that use the wide and diverse museum collection. The service makes the Museum space more interesting. It attracts the most numerous group of museum visitors-young people. The widespread use of gadgets and effective extraction of information allow the student to use the services to find information important for her/his study.

In particular, the History Museum of PetrSU collects many various award diplomas, cups of student sport achievements, and other awards. There is no sense to represent 
all of them physically in the exhibition room. Nevertheless, getting acquainted with the sports life of the University, in addition to the installed exhibits (such as photos, newspaper clippings), the visitor uses the exhibition service to analyze the information not presented in the exhibition room. The service supports answering certain typical questions, e.g., about the time of the appearance of the sport at the University, about the coach, or about the degree of popularity.

For this kind of recommendations, local ranking can be used. In particular, $r_{v}=$ $1 / \rho(u, v)$, where the distance $\rho(u, v)$ shows the relation level of information fact $v$ to the recently studied exhibit or fact $u$ (for $u, v \in V$ ). The recommendation assistance is online (i.e., implementing smart navigation). An effective visualization can employ the star graph model, where the internal node $u$ has a small set of rays (leaves) to show the recommended facts and their interest level (rank).

Enrichment service The service supports modification (evolution) of the semantic network by museum personnel and visitors (i.e., implementing collective intelligence). A museum visitor can enrich descriptions of studied exhibits (e.g., adding annotations). A personal mobile device (e.g., smartphone) becomes a primary access tool for this service. First, annotation is useful when the visitor adds descriptions about an object (e.g., facts from an eyewitness of the event), which is particularly important in everyday life history. Second, visitors can make the routine work on establishing known history-valued relations between objects. The visitor adds some relation (together with its description), and museum personnel moderate the correctness and value.

The museum collection is for modern history, preserving the events of the recent past and being constantly updated with modern exhibits. The collection often provokes visitors' own memories of the University life. The service captures these memories and turns them into exhibits. Museum collection has many exhibits for which information needs clarification: the date of creation of photos are sometimes specified approximately, in group photos are only individual persons. There are many exhibits the purpose and work of which is not always fully understood. In particular, old devices and mechanisms that were used in the educational process and now lost their importance. The service supports collecting this clarification information from visitors and experts.

In the case of university life history, the role of visitors as potential sources of new information is essential. Such visitors are direct participants of the events for describing which the exhibits are collected. Indeed, the verification problem of provided information is open. The museum personnel must provide expertise to determine the value of the provided information and to make decision on inclusion to the museum collection.

This service can use ranking for quality evaluation. In particular, let the initial semantic network $G$ have ranks structure $R_{G}=\left\{r_{G}\right\}$. After community-based enrichment, the new semantic network is $G^{*}$ has another ranks structure $R_{G^{*}}=\left\{r_{G^{*}}\right\}$. Analysis of the difference between $R_{G}$ and $R_{G^{*}}$ supports quantitative evaluation of the added value to the $\mathrm{CHH}$ knowledge the museum collects. 


\section{Conclusion}

This paper presented our view on smart museum information services in respect to their role for assisting cultural and historical heritage activity of both museum visitors and personnel. We reviewed the smart museum concept based on the recent progress in ICT. We presented the basic forms of such services applicable for $\mathrm{CHH}$ activity within a smart museum. Our service development is based on applying the semantic network model for integrating heterogeneous $\mathrm{CHH}$ knowledge. Data mining in a semantic network is reduced to the ranking problem, which in turn is used for constructing the services. The applicability and effectiveness is discussed based on the case study of the History Museum of PetrSU, where the proposed services are developed for the $\mathrm{CHH}$ preservation, transmission, and research needs.

\section{Acknowledgements}

This research is financially supported by the Ministry of Education and Science of Russia within project \# 2.5124.2017/8.9 of the basic part of state research assignment for 2017-2019. The work is implemented within the Government Program of Flagship University Development for Petrozavodsk State University in 2017-2021.

\section{References}

Alzahrani, A.A., Loke, S.W., Lu, H. (2014). An advanced location-aware physical annotation system: From models to implementation. Journal of Ambient Intelligence and Smart Environments 6(1), 71-91

Amato, F., Moscato, V., Picariello, A., Colace, F., Santo, M.D., Schreiber, F.A., Tanca, L. (2017). Big data meets digital cultural heritage: Design and implementation of scrabs, a smart context-aware browsing assistant for cultural environments. J. Comput. Cult. Herit. 10(1), $6: 1-6: 23$

Augusto, J., Callaghan, V., Cook, D., Kameas, A., Satoh, I. (2013). Intelligent environments: a manifesto. Human-centric Computing and Information Sciences 3(1), 1-18

Bizer, C., Lehmann, J., Kobilarov, G., Auer, S., Becker, C., Cyganiak, R., Hellmann, S. (2009). DBpedia - a crystallization point for the Web of Data. Web Semantics: Science, Services and Agents on the World Wide Web 7, 154-165

Bowen, J.P., Filippini-Fantoni, S. (2004). Personalization and the web from a museum perspective. In: Proc. Museums and the Web 2004. pp. 1-22. Archives \& Museum Informatics

Chianese, A., Piccialli, F., Valente, I. (2015). Smart environments and cultural heritage: A novel approach to create intelligent cultural spaces. Journal of Location Based Services 9(3), 209234

Doerr, M. (2003) The CIDOC conceptual reference module: an ontological approach to semantic interoperability of metadata. AI magazine 24(3)

Kalus, M. (2007). Semantic networks and historical knowledge management: Introducing new methods of computer-based research. The Journal of the Association for History and Computing 10

Korzun, D. Service formalism and architectural abstractions for smart space applications. In: Proc. 10th Central \& Eastern European Software Engineering Conference in Russia (CEESECR 2014).pp. 19:1-19:7. ACM 
Korzun, D. (2016). Designing smart space based information systems: The case study of services for IoT-enabled collaborative work and cultural heritage environments. In: Frontiers in Artificial Intelligence and Applications. Volume 291: Databases and Information Systems IX. pp. 183-196. IOS Press

Korzun, D. (2016). On the smart spaces approach to semantic-driven design of service-oriented information systems. In: Proc. 12th Int'l Baltic Conf. on Databases and Information Systems (DB\&IS 2016). pp. 181-195. Springer International Publishing

Korzun, D. G., Marchenkov, S. A., Vdovenko, A. S., Petrina, O. B. (2016). A Semantic Approach to Designing Information Services for Smart Museums. International Journal of Embedded and Real-Time Communication Systems (IJERTCS), 7(2), 15-34

Korzun, D., Varfolomeyev, A., Yalovitsyna, S., Volokhova, V. (2017). Semantic infrastructure of a smart museum: toward making cultural heritage knowledge usable and creatable by visitors and professionals. Personal and Ubiquitous Computing 21, 345-354

Korzun, D., Yalovitsyna, S., Volokhova, V. (2018). Smart museum information services to assist preservation, transmission and research in cultural and historical heritage domain. In: CEUR Workshop Proc. 13th Int'l Baltic Conf. on Databases and Information Systems (DB\&IS 2018). pp. 43-52. CEUR

Kuflik, T., Wecker, A., Lanir, J., Stock, O. (2015). An integrative framework for extending the boundaries of the museum visit experience: linking the pre, during and post visit phases. Information Technology \& Tourism 15(1), 17-47

Lepouras, G., Naudet, Y., Antoniou, A., Lykourentzou, I., Tobias, E., Rompa, J. (2015). Museum personalization based on gaming and cognitive styles: The BLUE experiment. Int. J. Virtual Communities Soc. Netw. 7(2), 1-30

Lora, A., Rogier, B., Lloyd, R., Peter, G., Natalia, S., Yiwen, W. (2007). Personalized museum experience: The Rijksmuseum use case. In: Proc. Museums and the Web 2007. Archives \& Museum Informatics

Marchenkov, S., Vdovenko, A., Petrina, O., Korzun, D. (2017). Smart museum of everyday life history in Petrozavodsk State University: Software design and implementation of the semantic layer. In: Proc. 21st Conf. Open Innovations Association FRUCT. pp. 224-230. IEEE

Moraes, M., Bertoletti, A., Costa, A. (1999). The SAGRES virtual museum with software agents to stimulate the visiting of museums. In: Proc. World Conf. on the WWW and Internet (WebNet 99). pp. 770-775. AACE

Mouromtsev, D., Haase, P., Pavlov, D., Cherny, E., Andreev, A., Spiridonova, A. (2015). Towards the linked Russian heritage cloud: Data enrichment and publishing. In: The Semantic Web. Latest Advances and New Domains (ESWC2015). pp. 637-651. LNCS 9088, Springer

Petrina, O.B., Korzun, D.G., Volokhova, V.V., Yalovitsyna, S.E., Varfolomeyev, A.G. (2017). Semantic approach to opening museum collections of everyday life history for services in Internet of Things environments. International Journal of Embedded and Real-Time Communication Systems (IJERTCS). Special Issue on Big Data Analytics and Intelligent Environments in Internet of Things. 8(1), 31-44

Ruotsalo, T., Haav, K., Stoyanov, A., Roche, S., Fani, E., Deliai, R., Makela, E., Kauppinen, T., Hyvonen, E. (2013). SMARTMUSEUM: A mobile recommender system for the Web of Data. Web Semantics: Science, Services and Agents on the World Wide Web 20, 50-67

Schuster, E.: A custom fit: Personalizing experiences using technology. Dimensions, URL: http://www.astc.org/astc-dimensions/a-custom-fit-personalizing-experiences-usingtechnology/

Simou, N., Chortaras, A., Stamou, G., Kollias, S. (2017). Enriching and Publishing Cultural Heritage as Linked Open Data. In Mixed Reality and Gamification for Cultural Heritage. pp. 201-223. Springer International Publishing 
Smirnov, A., Shilov, N., Kashevnik, A. (2012). Ontology-based mobile smart museums service, approach for small \& medium museums. In: Proc. of the 4th Int'l Conf. on Advances in Future Internet (AFIN 2012). pp. 48-54. IARIA

Torre, I. (2013). Interaction with linked digital memories. In: Berkovsky, S., Herder, E., Lops, P., Santos, O.C. (eds.) Late-Breaking Results, Project Papers and Workshop Proc. the 21st Conf. on User Modeling, Adaptation, and Personalization (UMAP 2013). Proc. Workshop on Personal Access to Cultural Heritage (PATCH 2013). CEUR Workshop Proceedings, vol. 997, pp. 80-87

Vassilakis, C., Poulopoulos, V., Antoniou, A., Wallace, M., Lepouras, G., Nores, M.L. (2018). exhiSTORY: Smart exhibits that tell their own stories. Future Generation Computer Systems $81,542-556$

Received October 31, 2018 , accepted December 13, 2018 